\title{
Necessity and Ideas on the Construction of Case Base of Geological Disaster Prevention Course for Graduate Students
}

\author{
You-li FENG \\ School of Resources and Environment \\ Henan Polytechnic University \\ JIAOZUO, P. R. China \\ fengyouli66@163.com
}

\author{
Meng-tao WANG \\ School of Resources and Environment \\ Henan Polytechnic University \\ JIAOZUO, P. R. China \\ 2932403066@qq.com
}

\author{
Li-jing YU \\ School of Resources and Environment \\ Henan Polytechnic University \\ JIAOZUO, P. R. China
}

\begin{abstract}
There are number of casualties and economic losses alarming caused by geological disasters each year in China. It is serious to prevent and control geological disaster. In order to make graduate students master the theory and practical skills of geological disaster prevention and control work, the paper focuses on the construction and significance of geological hazard case database. We summarize the work of the practical problems and put forward the construction of geological disaster case base ideas. The construction of the case base adopts the structure from the total to the minute and strictly follows the principle of comprehensiveness, extensiveness, typicality and gradient. At present, some domestic geological disaster control engineering design and related colleges and universities of geological hazard risk assessment courseware have been collected. It is necessary for course of geological disaster prevention and control to use case teaching method; it will bring innovation to teaching curriculum, training for the geological disaster prevention and treatment of talents, and promote the work of geological disaster prevention and control to a new level.
\end{abstract}

Keywords-Case Teaching Method, Geological Disaster Prevention and Control, Case Base Construction, Innovation of Teaching

\section{The Necessity of CASE BASEd CONSTRICTION}

\section{A. The applying history of case teaching method}

Case method of teaching was first applied with the legal and the medical profession, then, applied to the management of academia. In 1921, Copporand published the first case set, and full of promotion in the Harvard Business School, which laid the case for pedagogy teaching practice basis [1]. Compared with a traditional lecture format, assigning small groups of students to examine literature case studies encourages more active engagement with the course material and stimulates improved class discussion[2]. The biggest advantage of case teaching is that it can help students apply their knowledge to solve the problem of disjointed theory and practice. Harvard
Business School requires that each MBA student must discuss more than 700 cases during the course of study, demonstrating the importance of case teaching. Research and promotion of case teaching method can help to further enhance the teaching level, training high-quality personnel. China's teaching system is facing a severe challenge; hoping to improve the teaching methods through case teaching, improve teaching quality [3].

\section{B. The significance of case-base construction}

The quality and quantity of the construction of the case base determines the effectiveness of the case teaching to a large extent and plays a key role in case teaching. There are three aspects significance:

1) It can not only help the students to finish and master teaching contents, but also use the case database to train the students ' ability of comprehensive application of knowledge and improve the students' comprehensive quality, and to promote the comprehensive quality of the students and practical teaching reformation [4].

2) Through the establishment of the case base, teachers can be targeted according to the teaching content and teaching objectives selected from the case base case, is conducive to communication and exchange between teachers, both to achieve the sharing of teaching resources, but also as other teaching methods such as guide, discussion-style teaching method of useful supplement [5].

3) Through the construction and application of the teaching case base, the instructors not only need to integrate the knowledge of the subject, but also need to master the basics of other disciplines related to the case. This requires teachers to use their spare time to constantly "charge", so that they become "erudite", so as to ease in the classroom [6]. 


\section{Status and development trends of geological disaster prevention and control}

The study of geological disasters in foreign countries is mainly reflected in the following aspects:

1) Deepening the research on the mechanism of geological disasters from the deeper and wider angle, using the modern scientific and technological means and methods to continue to strengthen the in-depth study about characteristics, classification, cause mechanism, forecast and prevention and treatment of single geological disasters.

2) Pay attention to the technical methods of disaster mapping and the application of "3S" technology, use modern technology (such as 3S) to carry out regional assessment of geological disasters in small and medium watersheds, identify the temporal and spatial distribution of geological disasters. While linking this risk level to the land price so that the results of geological disasters research directly for the public service;

3) Significant progress has been made in the early warning system of regional geological disasters and the disaster management information system in typical areas. The United States Geological Survey and the Bureau of Meteorology, in the mid-80s of 20 century in the San Francisco Bay Area, the establishment of the landslide early warning system, the first use of television and radio more accurately published a large number of landslides have been induced in the area by cumulative rainfall of $800 \mathrm{~mm}$ in May 12-21, 1986. California, with remote sensing image interpretation, carried out 1: 2.4 million scale landslide mapping, Colorado carried out geological disasters zoning, divided into high, medium and low levels of geological disaster risk areas, are openly evaluated result for the public reference; California, Colorado, Oregon, Washington and other places, the use of satellite communications technology to carry out real-time monitoring of landslides. Thence the research of regional geological disaster early - warning system is developing rapidly in the world.

4) The economic benefits of the research results of geological disasters are considerable, and the results can be shared by the society, serve the social economy. Some developed countries have prevention and control of geological disasters and urban greening work organically integrated, protective engineering requirements not only have an effective prevention and control of geological disasters, but also to beautify the environment, and the protection of the project has become a unique landscape

Now, Chinese geological disaster prevention and control work can be timely and effective, it has got considerable progress. After the 90s of last century, scientists carry on indepth study about the type of geological disasters, characteristics, factors, distribution and the law of regional development in China and put forward many new theories and new ideas. In particular, quantitative methods, such as gray system model, genetic algorithm, cellular automata and BP neurons, are used to research and manage geological disasters, which provide a powerful basis for the research and development of geological hazards. In the geological disaster prevention and control work, we still can do the following:
Timely and thorough deployment, the relevant staff in time for post-disaster resistance, leadership in-depth disaster areas to guide, to minimize the impact of disasters; Improve the emergency support system, rapid response to emergencies, the introduction of a number of corresponding disaster prevention and control regulations, steady and rapid prevention and control work; Early warning capacity, plan to start resolutely, reduce losses and the rate of casualties; China has realized that disaster prevention and control work focuses on "prevention", focusing on funding arrangements, technical support, increase the prevention and control of geological disaster prevention efforts, and popularize knowledge of prevention and control of geological disasters.

Prevention and control of geological disasters is our top priority. The cultivation of postgraduates with professional degree can help to cultivate new talents to prevent geological disasters quickly and become the backbone of geological disaster prevention and treatment. In order to make graduate students of the professional degree systematically master the theory and practical skills of geological disaster prevention and control work, it can be quickly put into such work after taking part in the work, and the course of geo-hazards prevention and control is very sufficiently important.

\section{Tentative IdeAs on Construction of CASE BASE OF Geological Prevention CoURSE}

\section{A. The principle of establishing the case base}

Case database is a resource library for case teaching. There is no better structure, the system perfect case database; case teaching will lose its due teaching effect. The construction of case base is the key factor of case teaching. The construction principles of the case base are as follows.

1) Comprehensiveness. Geological hazard prevention and control teaching case base not only covers the basic knowledge of geological disasters, but also includes its associated exploration technology applications such as remote sensing image interpretation, engineering geological mapping, geophysical exploration, mountain engineering, laboratory and field tests, test and simulation experiments, dynamic monitoring.

2) Extensive. Case selection should be extensive, as far as possible include five categories of geological disasters and all the different types of geological hazard classification. According to different types of cases, we can take more effective control measures to save manpower, material and financial resources.

3) Representativeness. The selected case is representative of some type of geological hazard. The typical case has general applicability, attracts more students to study this kind of geological disaster, so that students can use and master the knowledge and skills quickly.

4) Gradient. Cases should have a different degree of difficulty, it involve more cases from simple to complex, so as to meet the needs of different students, but also help step by step learning. Large-scale cases may make students lose patience, and small cases more likely to mobilize the interest of 
students, so that they can participate in the discussion actively [7].

\section{B. The structure of the case base}

Teaching case base of geological disaster prevention can be divided into five sub-databases: collapse case, landslide case, debris flow case, ground fissure case and ground collapse case. The contents of each case include case description and case notes of two parts.

Firstly, case descriptions include numbers, names, keywords, text and attachments. Case Number: It is usually the initial capital letter of the case disaster type plus the number, hidden point is HPYH + number. Case Name: The name of the case should indicate the time, location, type of geological disaster and the grade of the disaster. Case Keywords: To create accurate case keywords, so that teachers and students to retrieve cases. Case Attachment: including geological hazard survey methods and pictures, videos, documents and other data and achievements related to the case. Case text: it is an objective description of the case, the content on the choreography to be able to effectively cope with teachers and students $\mathrm{Q} \& \mathrm{~A}$, discussion and other interactive teaching implementation process. To collapse as an example .Case text description:

1) Natural geography, natural geological environment and man-made geological environment in the collapse area.

Describing the physical and geographical environment, micro-topography and the relationship between collapse disasters; lithologic characteristics, genetic types, structural features and geological age of rock and soil, the relationship between collapse, lithology and structure characteristics of rock and soil; Relationship between neotectonic movement, seismic activity and seismic intensity, collapse and earthquake, neotectonic movement; Hydrogeological conditions. The current situation of human economic activities and the development of long-term planning investigate the area of human engineering activities.

2) Geological factors, disaster elements, monitoring and prevention elements of collapse disaster body.

a) The location, shape, distribution elevation, geometric size and volume scale of the collapse body;

b) Geological structure of the collapse body, including strata, topography, geological structure, rock (soil) structure type, slope structure type;

c) Hydrogeological conditions of the collapsing body and the occurrence characteristics of the groundwater;

d) History of deformation and characteristics;

e) Collapse migration slope and collapse accumulation; f) Engineering geologic features of the surrounding geological body of the collapsing body;

g) Non-geological factors of pregnancy (such as rainfall, excavation, excavation, etc.) intensity, cycle and their role in the collapse and deformation of the role and impact;

h) Physical mechanics test and hydrogeological experiment parameters of the collapse rock body and environmental geology body.

Case studies give students practice identifying the parameters of a problem, recognizing and articulating positions, evaluating courses of action, and arguing different points of view [8].

\section{CONCLUSION}

As a support system of case teaching, the case base organically links the relevant knowledge and skills related to geological disaster prevention and control so that the course of geological disaster prevention and control can be presented to teachers and students in a new way. This approach can realize communication between teacher and student. It has more significance for students to learn and master the relevant knowledge and skills. After the case of the rich and expanding, geological disaster prevention and control case library will become a resource for the teaching of geological disaster prevention and control work to provide protection.

\section{REFERENCES}

[1] L. Zhu, "Analysis of Case Teaching Method".Journal of Yunnan University of Finance and Economics, 2003, Vol .19, pp.120 - 123.

[2] G. Michael, M Tamara, and S.L. Zheng. "Teaching with the case study method to promote active learning in a small molecule crystallography course for chemistry students." Journal of Chemical Education.2016, Vol .93, pp 270-274.

[3] Z.Y. He. "Considerations on the Construction of Chinese Enterprise Management Case Base" Contemporary Finance \& Economics, 2003 (1): pp 93 - 95.

[4] Y. Yang, Y. Zhang, and Q.F. Li, "Construction and consideration of case - teaching Library of Biochemistry in TCM Colleges and Universities [J]. Journal of Yunnan College of Traditional Chinese Medicine, 2010, Vol .23, pp 60-62.

[5] J. Liang, "Teaching Case Database Construction Problems and Countermeasures". Science and Education and Culture: the next issue, 2012 (3): pp35-36.

[6] M. Wang, Y. Zhang and L.F. Ling,. "Application of case teaching method in biochemistry teaching in medical colleges" . 2012,Vol.29, pp103-105.

[7] B.Yang and D.L. Chen,. "Management accounting teaching case database construction of a Number of thinking" Higher Education Journal, 2015 (14), pp56-57.

[8] G.. Tatyana, A. Gayane, and A. Natalia., "Case study as an active method of teaching business English. procedia-social and behavioral sciences", 2015, Vol. 166, pp292-295. 